\title{
Assessing the Impact of Biologically Synthesized ZnO Nanoparticles as Source of Nutrient on the Growth of Zea mays L.
}

\section{Sumera Sabir}

Government College University Faisalabad

\section{Muhammad Asif Zahoor}

Government College University Faisalabad

Muhammad waseem

Government College University Faisalabad

Muhammad Hussnain Siddique

Government College University Faisalabad

Muhammad Shafique

Government College University Faisalabad

Muhammad Imran

COMSATS University Islamabad

\section{Sumreen Hayat}

Government College Women University Faisalabad

Imran Riaz Malik

University of Sargodha

Saima Muzammil ( $\square$ saimamuzammil83@gmail.com)

Government College University Faisalabad

Original article

Keywords: ZnO nanoparticles, Zea mays L, Growth parameters, Nanofertilizers

Posted Date: April 7th, 2020

DOl: https://doi.org/10.21203/rs.3.rs-20629/v1

License: (c) (i) This work is licensed under a Creative Commons Attribution 4.0 International License.

Read Full License 


\section{Abstract}

Nano-fertilizer(s), an emerging field of agriculture, is alternate option for enhancement of plant growth replacing the synthetic fertilizers. For example, zinc oxide nanoparticles (ZnO NPs) can be used as the zinc source for plants. The present investigation was carried out to assess the role of ZnO NPs in growth promotion of maize plants. ZnO NPs were synthesized using Bacillus sp ., which were characterized using Scanning Electron Microscope (SEM), Transmission Electron Microscope (TEM) and X-ray diffraction (XRD). The different concentrations of ZnO NPs ( $\mathrm{i}$. e . . 0, 2, 4, 6, 8, $16 \mathrm{mg} / \mathrm{L}$ ) for growth enhancement of maize ( Zea mays L.) were explored in pot culture experiment. It was observed that size of $\mathrm{ZnO}$ NPs ranged between 16 and $20 \mathrm{~nm}$. A significant increase in growth parameters like shoot length $(61.7 \%)$, root length $(56.9 \%)$ and significantly higher level of protein was observed in the treated plants as compared to control The overall pattern for growth biomarkers including the protein contents was maximum at $8 \mathrm{mg} / \mathrm{L}$ of $\mathrm{ZnO} \mathrm{NPs}$. It was observed that application of biologically synthesized ZnO NPs has improved majority of growth biomarkers including plant growth parameters, protein contents and leaf area. All these parameters were positively influenced by ZnO NPs. Therefore, biosynthesized ZnO NPs could be considered as an alternate source of nutrient in $\mathrm{Zn}$ deficient soils for promoting the modern agriculture.

\section{Introduction}

Nanotechnology has led to new revolutions in every field of science through the incorporation of nanoparticles in various industrial and medical products such as ceramic materials, cosmetic products and food products (Lee et al. 2010; Rico et al. 2011). Efforts are also carried out to understand the role of nanoparticles in the field of agriculture particularly for plant growth. These nanoparticles are becoming a promising strategy to enhance plant growth and productivity due to the presence of exceptional properties such as small size, high surface area/volume ratio, high adsorption, large number of reactive sites, high catalytic activity and high chemical stability as compared to bulk ion (Moatamed et al. 2019). These properties make the nanoparticles highly reactive upon their exposure to biological systems. Many researchers focused on the bioenvironmental impact of nanoparticles particularly their effects on animals, plants and microbes (Ibrahim et al. 2016). These studies focused mainly on the toxic impact of nanoparticles to environment as they often had used high doses of nanoparticles for short periods of time (Khatun et al. 2018). Mostly, these studies mentioned the negative impacts of nanoparticles to both environment and plants. Contrary to that, relatively fewer studies examined the beneficial effects of nanoparticles on plants as evidenced from literature (Rizwan et al. 2019). Recently, nanoparticles have gained a lot of attention for its usage in agriculture, particularly in the context of fertilizers with the emergence of novel technique as nanofertilizer (Dimkpa, 2014).

The exceptional properties of metallic nanoparticles enhance the bioavailability and uptake of micronutrients to the plants, thus enhancing the overall growth of the plants (Baker et al. 2017). The added advantage of nanofertilizers is the potential reduction in the loss of nutrients in to the soil compared to conventional fertilizer application, which ultimately reduces the application rates of fertilizer. 
Microelements, although required in small quantity, but are essential for plant development and yield. Among these nutrients, zinc plays a significant role in the growth of the plants, animals and humans as its deficiency may lead to several disorders (Ibrahim et al. 2016). Plants generally require $\mathrm{Zn}$ for carbohydrate metabolism and for gene expression related to environmental stress (Sabir et al. 2014). Usually, zinc is applied, as fertilizers in the form of soluble salt, that helps to assimilate the $\mathrm{Zn}$ which may cause environmental problems.

Maize is very sensitive to zinc deficiency and may lead to yellow stripe appearances on leaves within two weeks of growth. It may result in decreased photosynthesis, stomatal conductance, efficacy of photosystem, biomass, and Zn concentration in plants (Mattiello et al. 2015). Therefore, it is very essential to determine the $\mathrm{Zn}$ deficiency carefully before heavy damage may occur to the crop. To cope with these challenges, use of nanotechnology could be a better substitute to chemicals because of highly

small size, ZnO NPs could easily absorbed and transmitted to the plant and decrease the Zn deficiency in the plant. Among these, ZnO NPs have gained more attention for their use in agriculture as United States Food and Drug Administration (USFDA) recognizes it as a safe substance. Moreover, antimicrobial properties of ZnO NPs and low cost of production have compelled the researcher to consider nanoparticles for application in food and agriculture industries (Batsmanova et al. 2013). There are several ways to synthesize ZnO NPs including physical, chemical and biological methods. Both physical and chemical methods are not only expensive but they also involve generation of toxic secondary metabolites. Biosynthesis (such as involvement of bacterial species) to prepare ZnO NPs would be preferred option to existing methods (Singh et al. 2014) as it is environmentally benign and less expensive. Therefore, the present study was conducted to investigate the potential of biosynthesized ZnO NP as source of Zn nutrient on the growth of maize (Zea mays L.). As a result, this study would offer valuable insight for the development of nanomaterial as micronutrient source for crop production.

\section{Materials And Methods}

\section{Plant Materials}

Seeds of maize (Zea mays L.) were obtained from Ayub Agricultural Research Institute, FaisalabadPakistan. Healthy looking and uniform sized seeds were surface-sterilized with $1 \%$ sodium hypochlorite solution for $10 \mathrm{~min}$, followed by repeated washing with double distilled water (Faizan et al. 2016).

\section{Biosynthesis Of Zno Nanoparticles}

Bacillus subtilis inoculum (obtained from department of Microbiology, Government College University, Faisalabad-Pakistan) was added in $100 \mathrm{ml}$ of nutrient broth. Zinc nitrate was then dissolved in the bacterial solution under constant stirring using magnetic stirrer. After complete dissolution of the mixture, the solution was kept under vigorous stirring at $150^{\circ} \mathrm{C}$ for $5-6 \mathrm{~h}$, allowed to cool at room temperature 
and the supernatant was discarded. The pale white solid product obtained was centrifuged twice at $4500 \mathrm{rpm}$ for $15 \mathrm{~min}$ after thorough washing and dried at $80^{\circ} \mathrm{C}$ for $7-8 \mathrm{~h}$ (Yusof et al. 2019).

\section{Characterization Of Biosynthesized Zno Nps}

The biosynthesized ZnO NPs were characterized through UV-Visible spectroscopy, X-ray diffraction (XRD), Scanning Electron Microscopy (SEM) and Transmission electron Microscopy TEM as described by Wang et al. (2020).

\section{Uv Visible Spectroscopy Zno Nps}

For UV-Vis spectroscopy, ZnO NPs concentration $(5 \mathrm{mg} / 20 \mathrm{ml})$ was prepared by diluting in de-ionized water and spectrum scans was performed in a wavelength range $300-700 \mathrm{~nm}$ using HACH DR5000 spectrophotometer to find wavelength for maximum absorbance.

\section{X-ray Diffraction (xrd)}

Dried sample of nanoparticles was used for the XRD. The crystalline size of the ZnO NPs was measured with an analytical X'Pert, X-ray diffractometer using CuKa1 radiations $(\lambda=1.540598 \AA$ ), at $40 \mathrm{kV}$ and $40 \mathrm{~mA}$ with a divergence slit of $10 \mathrm{~mm}$. The $2 \theta$ range was acquired from $30^{\circ}$ to $80^{\circ}$ and JCPDS Cards were used as standards to find the respective phases of the particles. The crystallite size was calculated by Debye-Scherer equation (Mohan Kumar et al. 2013).

\section{Transmission Electron Microscopy (tem)}

Transmission electron microscopy was used to determine the size, shape and morphology of nanoparticles. ZnO nanoparticles dispersions were diluted to $100 \mu \mathrm{g} / \mathrm{mL}$ in distilled water or DMEM. The samples were prepared by dropping $10 \mu \mathrm{L}$ aliquots of the particle suspensions onto a copper grid and then allowed to dry (Wang et al. 2009). TEM was performed on JEOL JEM-1400 instrument (Jeol LTD, Tokyo, Japan). For SEM images, dried particles were mounted on aluminum stub and coated with gold to get better contrast.

\section{Scanning Electron Microscopy (sem) Of Zno Nps}

SEM analysis was performed with a scanning electron microscope (JEOL JSM-6480). It is used to determine topology and observation of surface (Ali et al. 2018).

\section{Dynamic Light Scattering (dls) Analysis}


Additionally, the size distribution and zeta potential of biosynthesized ZnO NPs was determined by dynamic light scattering (DLS) and and laser Doppler velocimetry (LDV) using a Malvern Zetasizer NanoZS zen 3600 (UK)(Wang and Keller, 2009).

Experimental design for Zea mays $L$

Seeds of Zea Mays L. were primed through soaking in different concentrations $(2,4,8,16 \mathrm{mg} / \mathrm{L})$ of biologically synthesized $\mathrm{ZnO}$ nanoparticles under optimised areation conditions for $24 \mathrm{~h}$ (Alharby et al. 2016). Seeds priming was followed by washing with distilled water and air drying under shade. These seeds were germinated in petri plates that were filled with soil and farmyard manure (in a ratio of 1:6). At 10 days after sowing (DAS), seedlings were transferred to pots filled with acid-washed sand allowed to grow under natural environmental conditions in Randomized Complete Block Design (RCBD) with triplicate of each treatment.

\section{Determination Of Total Leaf Protein}

Fresh leaves $(1 \mathrm{~g})$ were taken and crushed with the help of a mortar and pestle which were then mixed with extraction buffer (70 mM phosphate buffer; pH 7.0, 1 mM EDTA, 1 mM PMSF, 0.5\% Triton X 100, and $2 \%$ PVP. The mixture was centrifuged at $12,000 \times \mathrm{g}$ for $10 \mathrm{~min}$ at $4{ }^{\circ} \mathrm{C}$ and the supernatant was used further for estimation of protein contents. The total protein content of leaves was determined by the method followed by Bradford, (1976).

\section{Results}

\section{Characterization of ZnO NPs}

\section{UV-Visible Spectroscopy}

The UV-Visible spectroscopy revealed that tested ZnO NPs exhibited a well-defined plasmon band at the wavelength of $331 \mathrm{~nm}$ with an absorbance value of 1.89 (Fig. 1). The symmetrical shape of Plasmon band indicated the sharp particle size distribution with smaller particle size.

\section{Sem And Xrd Characteristics Of Zno Nps}

SEM studies were carried out to find out the surface morphology of synthesized $\mathrm{ZnO}$ nanoparticles. SEM studies showed ZnO NPs is in pure form and white colored (Fig. 2A.). The XRD spectra of the biosynthesized ZnO NPs are shown in (Fig. 2B.). The XRD spectra showed crystalline nature of the ZnO NPs. The average size obtained from the X-ray diffraction spectrum given in Fig. 2B. which was $11.9 \mathrm{~nm}$.

\section{Tem Characteristics Of Zno Nps}


TEM was used to determine the morphology and size of the supplied nanoparticles. As shown in Fig. 3B, $\mathrm{ZnO}$ nanoparticles are spherical and without aggregate with the size of $16-20 \mathrm{~nm}$ of diameter when diluted both in distilled $\mathrm{H}_{2} \mathrm{O}$ and in DMEM.

\section{Xps Analysis Of Zno Nps}

In XPS analysis, the percentage that each element represents is calculated from the peak area of the element using its relative and sensitive factors (RSF). To calculate the total amount of $\mathrm{Zn}$ and $\mathrm{O}$ we took the total area of the corresponding peak. Curve fitting analysis was made to determine the percentage of the element in each of the different links. The overview data shown in Fig. 4-A indicates that there is no contamination in the samples since only $\mathrm{Zn}, \mathrm{O}$ and $\mathrm{Au}$ (substrate) were detected in the XPS analysis. The amount of each element cannot be extrapolated from these graphs since the RSF of $Z n$ are higher than RSF of O (RSF Zn: 28.72 / RSF 0: 2.93), that is why the signal of Zn appears to be very increased in XPS graph. To have a reliable data of the percentage of each element we must calculate the area under the corresponding peaks and rely on numerical values.

\section{Size Distribution And Zeta Potential Analysis Of Zno Nps}

Stability of ZnO NPs were monitored by zeta potential (Fig. 5). The overall characteristics of biosynthesized ZnO NPs were represented in Table 1 which shows that the acquired data of the different tested parameters. While measurements taken from TEM images were consistent with the nominal size range for nano $\mathrm{ZnO}$ particles, sizes were significantly larger when the hydrodynamic radius was measured by DLS, especially for those samples diluted in DMEM. Interestingly, dispersion values show differences depending on the solvent used, as the Z-potential shows that dispersions in distilled $\mathrm{H}_{2} \mathrm{O}$ are moderately stable while particles diluted in DMEM were prone to aggregation. This correlates to that observed in TEM analysis.

Table 1

The average size and stability of biosynthesized ZnO NPs.

\begin{tabular}{|lll|}
\hline \multicolumn{3}{|c|}{ ZnO NPs } \\
\hline Dispersant & Distilled H2O & DMEM \\
\hline Size $(\mathrm{nm})(\mathrm{TEM})$ & $16.00 \pm 14.68$ & $20.00 \pm 16.38$ \\
\hline Size $(\mathrm{nm})(\mathrm{DLS})$ & $89.06 \pm 10.20$ & $165.6 \pm 10.85$ \\
\hline Pdl (DLS) & $0.352 \pm 0.09$ & $0.224 \pm 0.09$ \\
\hline Z-potential $(\mathrm{mV})(\mathrm{DLV})$ & $17.00 \pm 7.88$ & $-10.5 \pm 0.67$ \\
\hline Mobility $(\mu \mathrm{m} \mathrm{cm} / \mathrm{Vs})(\mathrm{DLV})$ & $1.335 \pm 0.10$ & $-0.8 \pm 0.05$ \\
\hline
\end{tabular}


Dispersant: The medium in which suspension made; ZnO NPs: Biosynthesized Zinc oxide nanoparticles.

\section{Effect Of Zno Nps On Growth Biomarkers}

The results demonstrated that biologically synthesized ZnO NPs facilitated the increase in root and shoot length at 35 DAS as compared to control. The maximum increase was observed for $8 \mathrm{mg} / \mathrm{L} \mathrm{ZnO} \mathrm{NPs} \mathrm{and}$ after a decrease in root and shoot length has been observed as shown in Fig. 6A. The maximum value for root length was $17.94 \mathrm{~cm}$ followed by $14.47 \mathrm{~cm}$ at $8 \mathrm{mg} / \mathrm{L}$ and $16 \mathrm{mg} / \mathrm{L} \mathrm{ZnO} \mathrm{NPs} \mathrm{concentration}$ respectively. The overall pattern for growth parameters at different concentration was in the order $8>16>$ $4>2>0 \mathrm{mg} / \mathrm{L}$ of ZnO NPs. Similar trend was observed for the root and shoot fresh and dry mass as shown in Fig. 6B. However, in case of the root fresh and dry mass, no significant difference was observed at $4 \mathrm{mg} / \mathrm{L}$ and $8 \mathrm{mg} / \mathrm{L}$ concentrations of ZnO NPs.

The maximum leaf area per plant $\left(56.12 \mathrm{~cm}^{2}\right)$ were recorded when $8 \mathrm{mg} / \mathrm{L}$ ZnO NPs concentration was used followed by $43.69 \mathrm{~cm}^{2}$ in plants treated with $4 \mathrm{mg} / \mathrm{L} \mathrm{ZnO} \mathrm{NPs}$. Statistically significant difference was observed in leaf area of plants treated with $8 \mathrm{mg} / \mathrm{LnO} N P s(P \leq 0.05)$ when compared to that of control as shown in Fig. 7A.

For the protein contents estimation of maize plant under various ZnO-NPs concentrations, plant treated with $8 \mathrm{mg} / \mathrm{L}$ concentration of ZnO NPs showed increased in protein contents (77.3\%) compared to that of control (Fig. 7B). Moreover, the increase in protein content was related to applied concentration of $\mathrm{ZnO}$ NPs. The pattern for the protein content in the plants treated was in order of $8>16>4>2>0 \mathrm{mg} / \mathrm{L}$.

\section{Discussion}

This study is conducted to evaluate the ZnO NPs potential for the plant growth. Morphology and the texture of the ZnO NPs synthesized using biological agent were determined through different techniques. As biological synthesis of nanoparticles is clean, cost effective, nontoxic and environmental friendly (Li et al. 2011) as compared to chemical synthesis, therefore ZnO NPs were synthesized using Bacillus sp. TEM image of ZnO NPs exhibited a small size and showed uniform crystal shapes. Moreover, close packing texture of ZnO NPs was revealed by the SEM image. It has been observed that the particles in the samples were compactly arranged and were almost spherical in shape. Motshekga et al. (2018) examined the morphology of ZnO NPs and found spherical shaped nanoparticles. In most of the studies, the size of ZnO NPs ranges between $40-75 \mathrm{~nm}$ but our study findings examined the ZnO NPs diameter in the range of 16-20 nm. Normally, the size of the nanoparticles depends on the experimental protocol used. As Khajeh and Golzary, (2014) synthesized ZnO NPs in hexagonal shaped with 11-25 nm size while Singh et al. (2014) found spherical shaped ZnO NPs with 35-80 nm in size using Pseudomonas aeruginosa. Crystal structure of the prepared biosynthesized nanoparticles was investigated using X-ray diffraction. Obtained crystal patterns confirm the patterns corresponding to $\mathrm{ZnO}$ and pure forms was confirmed (Ali et al. 2018). 
In our study, when applied nanoparticles to plants, increase in root length was observed with the increase in $\mathrm{ZnO}$ NPs concentration. One of the reasons is that there might be greater absorption of $\mathrm{Zn}$ in the root due to very small size of biosynthesized nanoparticle. Overall, the root and shoot length were higher (32\%) in the plants treated with biosynthesized ZnO NPs as compared to the control. The growth in root and shoot length reached maximum at $8 \mathrm{mg} / \mathrm{L}$ concentration of biosynthesized ZnO NPs.

The potential of zinc oxide nanoparticles to boost the growth and yield of crops has been studied as Prasad et al. (2012) studied the different concentrations of zinc oxide nanoparticles ( $25 \mathrm{~nm}$ in size) using priming of peanuts seeds and showed that $1000 \mathrm{ppm}$ concentration of ZnO NPs enhanced the seed germination and plant growth. This study demonstrated that treatment with $8 \mathrm{mg} / \mathrm{L} \mathrm{ZnO} \mathrm{NPs}$ concentration is most suitable for improving the root and shoot lengths. Batsmanova et al. (2013) demonstrated the positive influence of ZnO NPs used as micronutrient in cereal crops. Xun et al. (2017), showed the increase in the plant growth and photosynthesis due to ZnO NPs as compared to control in Zea Mays L plants. This improvement in root and shoot length could be attributed to smaller size of the nanoparticles as it there is possibility of higher $\mathrm{Zn}$ absorption by plant as compared to larger particles as described by Sabir et al. (2014). Similarly, Tripathi et al. (2017) observed higher absorption of $\mathrm{Zn}$ in the wheat seedlings treated with Zn NPs in comparison of larger zinc sulfate particles.

It has been studied that impact of nanoparticles on plants depends on method of their synthesis, dose, size as well as on the method of application to plants. For this study, seeds of Zea mays $L$ were primed with ZnO NPs and enhancement in growth parameters has been observed (Fig. 5, 6). According to our results, seed priming may be an effective method to enhance the growth parameters. Seed priming with ZnO NPs has been reported by Munir et al. (2016) and found higher concentration of $\mathrm{Zn}$ in roots and shoots than control. While comparing the green synthesized ZnO NPs $(35 \mathrm{~nm})$ with chemically synthesized ZnO NPs (48 nm) Singh et al. (2019) observed higher growth rate (root and shoot lengths) in green synthesized ZnO NPs relative to chemically synthesized ZnO NPs and ascribed it with smaller size of NPs.

As concern to nanoparticle dose, Hazeem et al. (2016) reported lower Zn concentration in cucumber shoot with Zn NPs concentration of $125 \mathrm{mg} / \mathrm{kg}$ than $25 \mathrm{mg} / \mathrm{kg}$ which could be due to higher Zn levels that deform the plant cells. While, contrary to this, Moghaddasi et al. (2017) reported higher Zn concentrations in plants treated with high NPs concentration and correlated it with higher penetration of NPs into plant cells However, more studies are required to understand the absorption mechanism within the plant cells. Positive influence of nanoparticles to plant depends on specific concentration of nanoparticles with specific plants. While, studying the ZNO NPs effect on tomato plants, Faizan et al. (2016) concluded that a significance increase in growth parameters depend on concentration and time of the treatment. Similar findings in terms of the increased growth biomarkers in maize plants (exposed to ZnO NPs) were observed in present study.

Significant increase in plant shoot and root growth and root area in Solanum lycopersicum, Vigna radiata and Cicer arietinum was observed by Mahajan et al. (2011) and Raliya et al. (2015) by treating the plants 
with ZnO NPs. In this study, ZnO NPs significantly impacted the leaf protein contents of maize The trend for protein contents was towards the higher concentration of the ZnO NPs. Rizwan et al. (2019) suggested that wheat plants treated with ZnO NPs had higher protein contents that accelerate the photosynthetic activity. In contrast, total protein contents in foxtail millet were not statistically different in ZnO NP-treated plants as compared to control (Kolencik et al. 2019).

Taken together, the current study clearly demonstrated positive influence of ZnO NPs on the the plant growth. Nano-priming could be an efficient technique for the better production of crops. So, the privilege to use nutrients such as $\mathrm{Zn}$ at the level of nanoscale might be a revolutionary step in agriculture. Overall, the results of this study could be helpful to the fertilizer industries to make a decision about the nanofertilizers production especially ZnO NPs that could be used as nutrient source to reduce the Zn deficiency in plants.

\section{Declarations}

\section{Authors' Contributions}

SM supervised the research work, manuscript write up and submission. SS practically conducted research work. SH participated in the study and paper correction. MAZ, MS, MW provided the theoretical guidance and technical support. MI, IRM and MHS helped to provide study materials and analysis of data. All authors read and approved the final manuscript.

Competing interests

The authors declare that they have no any conflict of interests.

\section{Funding}

This study was not funded by any funding agency. This work is supported by research fund of Department of Microbiology, Government College University Faisalabad Pakistan.

Ethics approval and consent to participate

This article does not contain any studies with human participants or animals performed by any of the authors.

Acknowledgements

Authors are highly thankful to Dr. Ricard Marcos Dauder, Departament de Genètica i de Microbiologia, Autonomous University of Barcelona, Spain for providing help to characterize the nanomaterials used in this study.

Availability of data and materials

The data and materials in the study are shared and available.

Consent for publication

Not Applicable 


\section{References}

Ali J, Irshad R, Li B, Tahir K, Ahmad A, Shakeel M, Khan NU, Khan ZUH (2018) Synthesis and characterization of phytochemical fabricated zinc oxide nanoparticles with enhanced antibacterial and catalytic applications. J Photochem Photobiol B 183: 349-356. DOI S1011-1344(18)30123-4 [pii]10.1016/j.jphotobiol.2018.05.006.

Alharby HF, Metwali EM, Fuller MP, Aldhebiani AY (2016) The alteration of mRNA expression of SOD and GPX genes, and proteins in tomato (Lycopersicon esculentum Mill) under stress of $\mathrm{NaCl}$ and/or $\mathrm{ZnO}$ nanoparticles. Saudi J Biol Sci 23: 773-781. DOI 10.1016/j.sjbs.2016.04.012S1319-562X(16)30024-9 [pii].

Batsmanova LM, Gonchar LM, Taran NY, Okanenko AA (2013) Proceedings of the international conference nanomaterials: Applications and properties 2:4, 2304-1862/2013/2(4)04NABM14(2) 04NABM14-1.

Baker S, Volova T, Prudnikova SV, Satish S, Prasad MNN (2017) Nanoagroparticles emerging trends and future prospect in modern agriculture system. Environ Toxicol Pharmacol 53: 10-17. DOI S13826689(17)30111-4 [pii]10.1016/j.etap.2017.04.012.

Bradford MM (1976) A rapid and sensitive method for the quantitation of microgram quantities of protein utilizing the principle of protein-dye binding. Anal Biochem 72: 248-254. DOI 0003-2697(76)90527-3 [pii]10.1006/abio.1976.9999.

Dimkpa CO (2014) Can nanotechnology deliver the promised benefits without negatively impacting soil microbial life? J Basic Microbiol 54: 889-904. DOI 10.1002/jobm.201400298.

Drazkiewicz M, Baszynski T (2005) Growth parameters and photosynthetic pigments in leaf segments of Zea mays exposed to cadmium, as related to protection mechanisms. J Plant Physiol 162: 1013-1021. DOI S0176-1617(05)00031-3 [pii]10.1016/j.jplph.2004.10.010.

Faizan M, Faraz A, Yusuf M, Khan ST, Hayat S (2018) Zinc oxide nanoparticle-mediated changes in photosynthetic efficiency and antioxidant system of tomato plants. Photosynthetica 56: 678-686. DOI 10.1007/s11099-017-0717-0.

Hazeem LJ, Bououdina M, Rashdan S, Brunet L, Slomianny C, Boukherroub R (2016) Cumulative effect of zinc oxide and titanium oxide nanoparticles on growth and chlorophyll a content of Picochlorum sp. Environ Sci Pollut Res Int 23: 2821-2830. DOI 10.1007/s11356-015-5493-410.1007/s11356-015-5493-4 [pii].

Hunt R, Causton DR, Shipley B, Askew AP (2002) A modern tool for classical plant growth analysis. Ann Bot 90: 485-488. DOI 10.1093/aob/mcf214. 
Ibrahim RK, Hayyan M, AlSaadi MA, Hayyan A, Ibrahim S (2016) Environmental application of nanotechnology: air, soil, and water. Environ Sci Pollut Res Int 23: 13754-13788. DOI 10.1007/s11356016-6457-z10.1007/s11356-016-6457-z [pii].

Khajeh M, Golzary AR (2014) Synthesis of zinc oxide nanoparticles-chitosan for extraction of methyl orange from water samples: cuckoo optimization algorithm-artificial neural network. Spectrochim Acta A Mol Biomol Spectrosc 131:189-194. DOI 10.1016/j.saa.2014.04.084. S1386-1425(14)00657-X [pii].

Khatun MA, Hossain MM, Bari MA, Abdullahil KM, Parvez MS, Alam MF, Kabir AH (2018) Zinc deficiency tolerance in maize is associated with the up-regulation of $\mathrm{Zn}$ transporter genes and antioxidant activities. Plant Biol (Stuttg) 20: 765-770. DOI 10.1111/plb.12837.

Kolencik M, Dávid E, Komár M, Urík M, Sebesta M, Dobrocka E, Cerny I, Illa R, Kanike R, Qian Y, Feng H, Orlova D, Kratosova G (2019) Effect of Foliar Spray Application of Zinc Oxide Nanoparticles on Quantitative, Nutritional, and Physiological Parameters of Foxtail Millet (Setaria italica L.) under Field Conditions Nanomaterials. 9:1559. DOI /2079-4991/9/11/1559.

Lee J, Mahendra S, Alvarez PJ (2010) Nanomaterials in the construction industry: a review of their applications and environmental health and safety considerations. ACS Nano 4: 3580-3590. DOI $10.1021 / \mathrm{nn} 100866 \mathrm{w}$.

Li X, Xu H, Chen ZS, Chen G (2011) Biosynthesis of nanoparticles by microorganisms and their applications. Journal of Nanomaterials 2011. DOI org/10.1155/2011/270974.

Mahajan P, Dhoke SK, Khanna AS (2011) Effect of nano-zno particle suspension on growth of mung (vigna radiata) and gram (cicer arietinum) seedlings using plant agar method. - j. Nanotechol. 2011: 696535. DOI journals/jnt/2011/696535/.

Mattiello E, Ruiz MHA, Neves JC, Ventrella MC, Araujo WL (2015) Zinc deficiency affects physiological and anatomical characteristics in maize leaves. J Plant Physiol 183: 138-143. DOI 10.1016/j.jplph.2015.05.014S0176-1617(15)00137-6 [pii].

Moatamed ER, Hussein AA, El-Desoky MM, Khayat ZE (2019) Comparative study of zinc oxide nanoparticles and its bulk form on liver function of Wistar rat. Toxicol Ind Health 35: 627-637. DOI $10.1177 / 0748233719878970$.

Mohan Kumar K, Mandal BK, Appala Naidu E, Sinha M, Siva Kumar K, Sreedhara Reddy P (2013) Synthesis and characterisation of flower shaped zinc oxide nanostructures and its antimicrobial activity. Spectrochim Acta A Mol Biomol Spectrosc 104: 171-174. DOI 10.1016/j.saa.2012.11.025 S13861425(12)01117-1 [pii].

Moghaddasi S, Khoshgoftarmanesh AH, Karimzadeh F, Chaney RL (2013) Preparation of nano-particles from waste tire rubber and evaluation of their effectiveness as zinc source for cucumber in nutrient 
solution culture. Sci Hort. 160:398-403. DOI: 10.1080/03650340.2016.1256475.

Mohd Yusof H, Mohamad R, Zaidan UH, Abdul Rahman NA (2019) Microbial synthesis of zinc oxide nanoparticles and their potential application as an antimicrobial agent and a feed supplement in animal industry: a review. J Anim Sci Biotechnol 10: 57. DOI 10.1186/s40104-019-0368-z368 [pii].

Motshekga SC, Sinha Ray S, Maity A (2018) Synthesis and characterization of alginate beads encapsulated zinc oxide nanoparticles for bacteria disinfection in water. J Colloid Interface Sci 512: 686692. DOI S0021-9797(17)31267-5 [pii]10.1016/j.jcis.2017.10.098.

Munir RI, Spicer V, Krokhin OV, Shamshurin D, Zhang X, Taillefer M, Blunt W, Cicek N, Sparling N, Levin DB (2016) Transcriptomic and proteomic analyses of core metabolism in Clostridium termitidis CT1112 during growth on alpha-cellulose, xylan, cellobiose and xylose. BMC Microbiol 16: 91. DOI 10.1186/s12866-016-0711-x10.1186/s12866-016-0711-x [pii].

Prasad TNVKV, Sudhakar P, Sreenivasulu Y, Latha P, Munaswamy V, Raja Reddy VK, Sreeprasad TS, Sajanlal PR, Pradeep T (2012) Effect of nanoscale zinc oxide particles on the germination, growth and yield of peanut. Journal of Plant Nutrition 35:6, 905-927. DOI: 10.1080/01904167.2012.663443.

Raliya R, Nair R, Chavalmane S (2015) Mechanistic evaluation of translocation and physiological impact of titanium dioxide and zinc oxide nanoparticles on the tomato (solanum lycopersicum I.) plant. metallomics 7: 1584-1594. DOI ncbi.nlm.nih.gov/pubmed/26463441.

Rico CM, Majumdar S, Duarte-Gardea M, Peralta-Videa JR, Gardea-Torresdey JL (2011) Interaction of nanoparticles with edible plants and their possible implications in the food chain. J Agric Food Chem 59: 3485-3498. DOI 10.1021/jf104517j.

Rizwan M, Ali S, Ali B, Adrees M, Arshad M, Hussain A, Zia Ur Rehman M, Waris AA (2019) Zinc and iron oxide nanoparticles improved the plant growth and reduced the oxidative stress and cadmium concentration in wheat. Chemosphere 214: 269-277. DOI S0045-6535(18)31776-4 [pii] 10.1016/j.chemosphere.2018.09.120.

Sabir S, Arshad M, Chaudhari SK (2014) Zinc oxide nanoparticles for revolutionizing agriculture: synthesis and applications. ScientificWorldJournal 2014: 925494. DOI 10.1155/2014/925494.

Singh BN, Rawat AKS, Khan W, Naqvi AH, Singh BR (2014) Biosynthesis of Stable Antioxidant ZnO Nanoparticles by Pseudomonas aeruginosa Rhamnolipids. PLoS ONE 9(9): e106937. DOI org/10.1371/journal.pone.0106937.

Tripathi DK, Mishra RK, Singh S, Vishwakarma K, Sharma S, Singh VP, Singh PK, Prasad SM, Dubey NK, Pandey AC, Sahi S, Chauhan DK (2017) Nitric Oxide Ameliorates Zinc Oxide Nanoparticles Phytotoxicity in Wheat Seedlings: Implication of the Ascorbate-Glutathione Cycle. Front Plant Sci 8: 1. DOI 10.3389/fpls.2017.00001. 
Wang D, Cui L, Chang X, Guan D (2020) Biosynthesis and characterization of zinc oxide nanoparticles from Artemisia annua and investigate their effect on proliferation, osteogenic differentiation and mineralization in human osteoblast-like MG-63 Cells. J Photochem Photobiol B 202: 111652. DOI S10111344(19)31283-7 [pii]10.1016/j.jphotobiol.2019.111652.

Wang P, Keller AA (2009) Natural and engineered nano and colloidal transport: role of zeta potential in prediction of particle deposition. Langmuir 25: 6856-6862. DOI 10.1021/la900134f.

Wang LS, Xiao MW, Huang XJ, Wu YD (2009) Synthesis, characterization, and photocatalytic activities of titanate nanotubes surface-decorated by zinc oxide nanoparticles. J Hazard Mater 161: 49-54. DOI 10.1016/j.jhazmat.2008.03.080S0304-3894(08)00432-9 [pii].

Xun H, Ma X, Chen J, Yang Z, Liu B, Gao X, Li G, Yu J, Wang L, Pang J (2017) Zinc oxide nanoparticle exposure triggers different gene expression patterns in maize shoots and roots. Environ Pollut 229: 479488. DOI S0269-7491(16)32862-7 [pii]10.1016/j.envpol.2017.05.066.

\section{Figures}

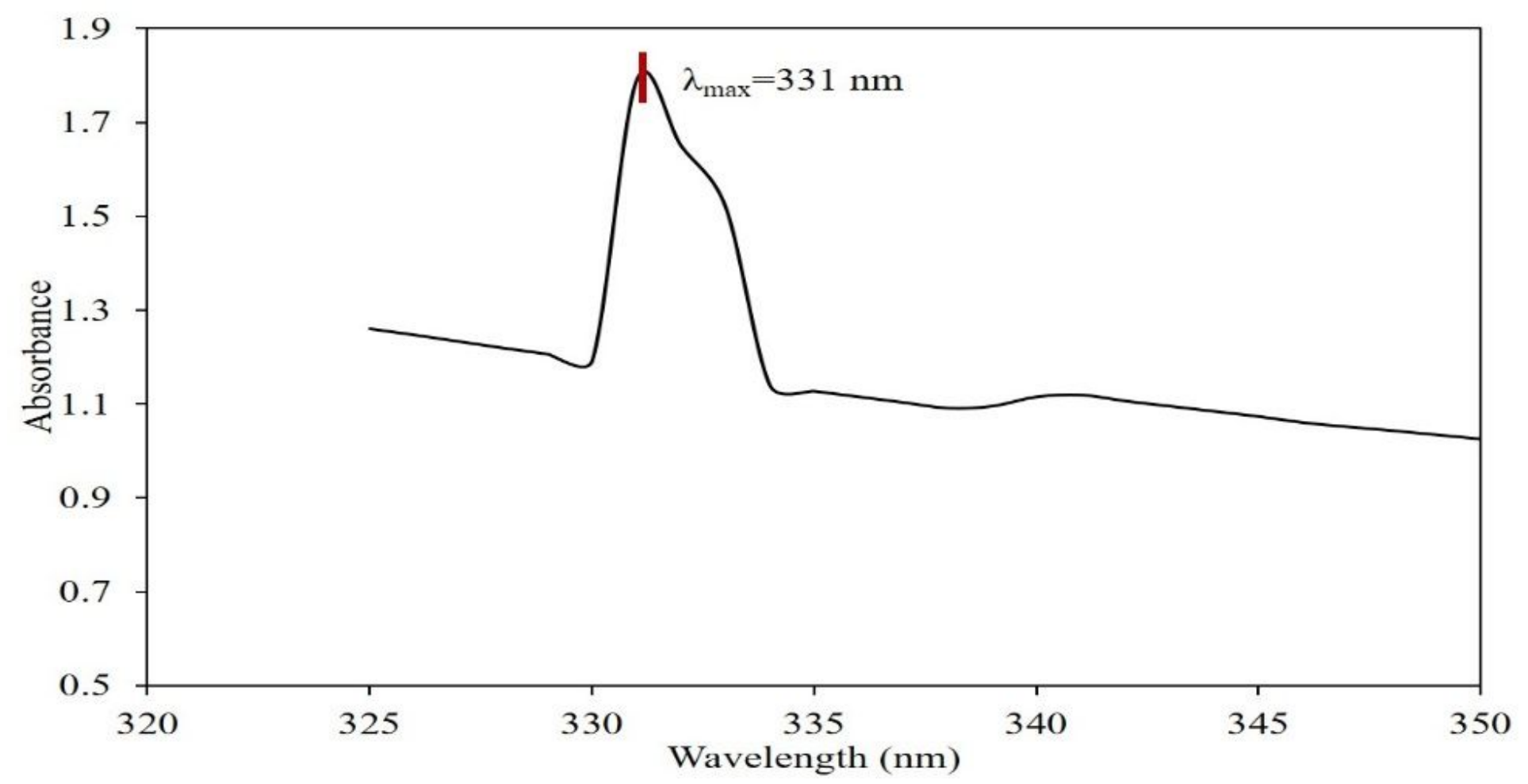

Figure 1

UV-Vis spectrum of biosynthesized ZnO NPs. 


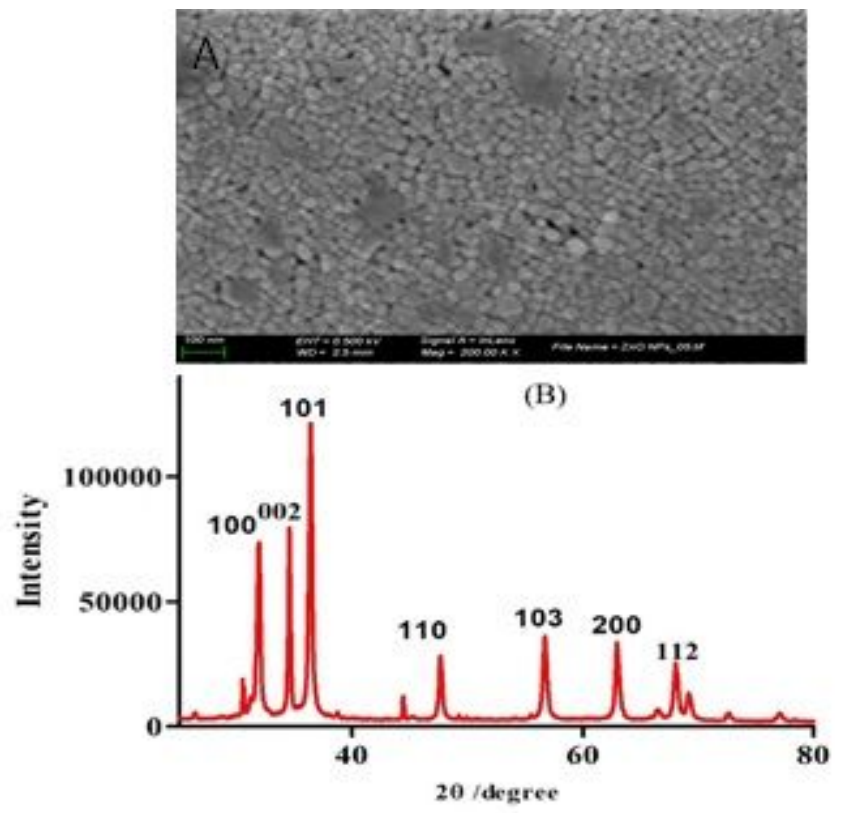

Figure 2

A) SEM micrograph of ZnO Nps; B) XRD spectra of biosynthesized ZnO NPs.
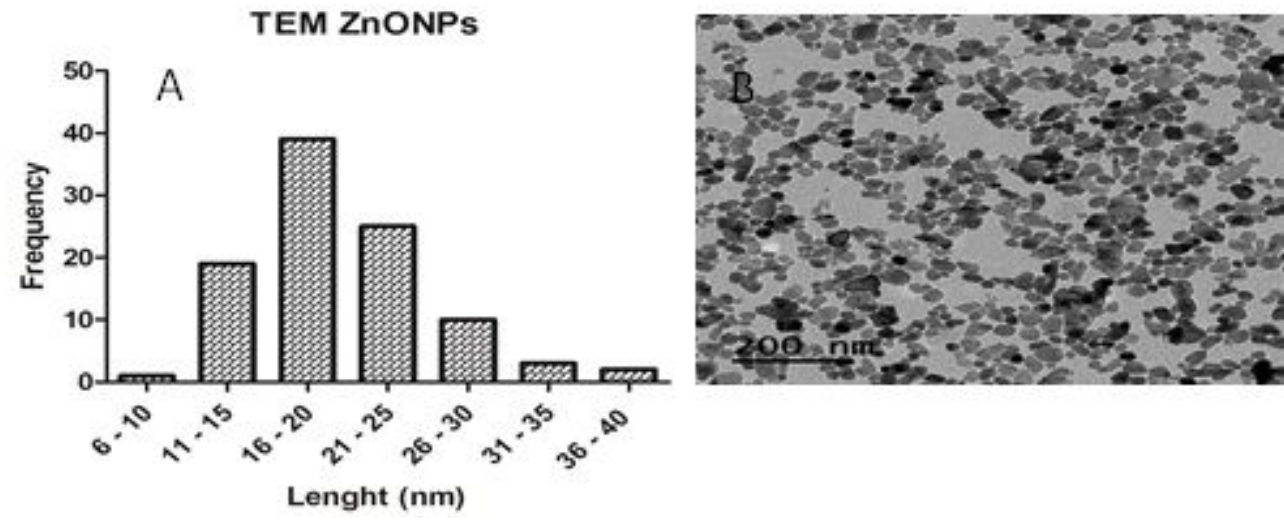

Figure 3

A) Diameter of biosynthesized ZnO NPs calculated by TEM; B) TEM micrograph of biosynthesized ZnO NPs. 

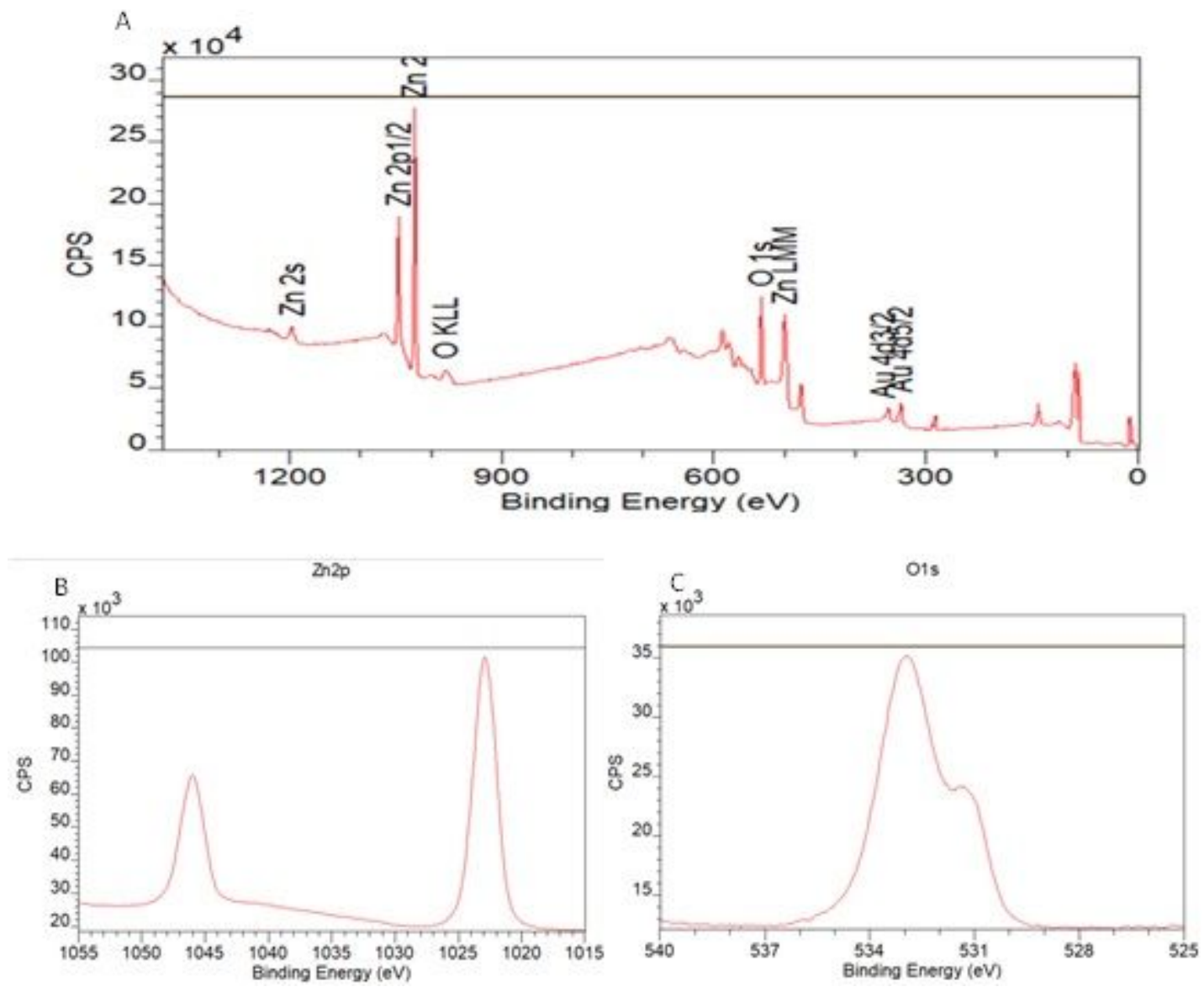

Figure 4

A) XPS wide survey spectra of biosynthesized ZnO NPs, (B, C) spectrum showing the data of Zn 2p (I) and $01 \mathrm{~s}$ (II) of biosynthesized ZnO nanoparticles. 

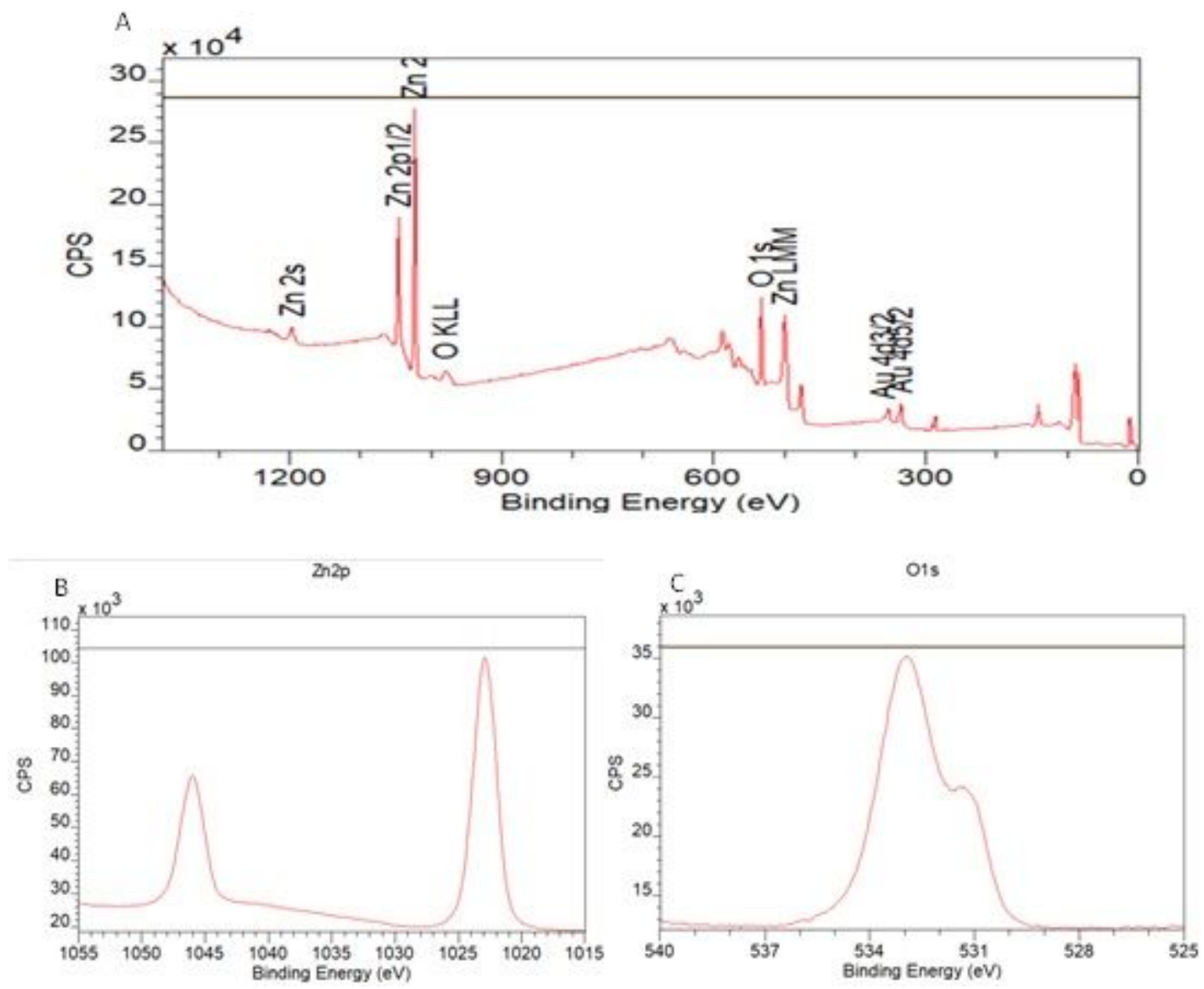

Figure 5

ZnO NPs. A) Size distribution and B) zeta potential
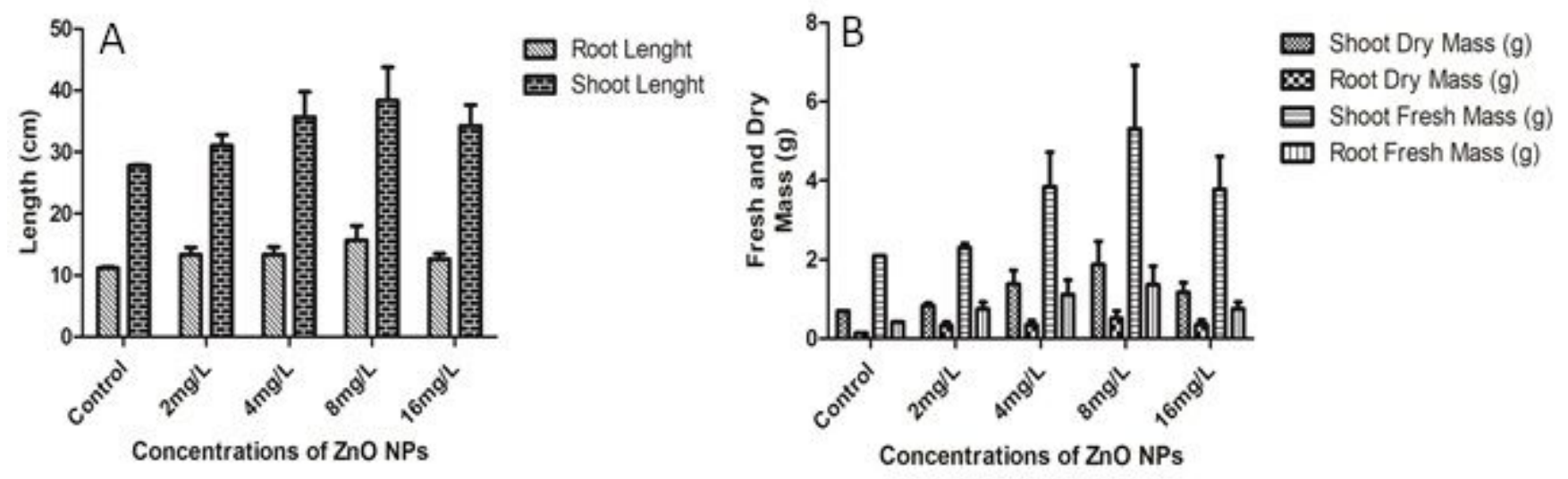

Figure 6

Effect of seed priming of Zea mays $L$ at different concentration of ZnO NPs at 35 DAS on growth parameters A) Root and shoot length; B) Root and shoot fresh mass (FM) and dry mass (DM) Values reported in the figures are means of triplicates with standard deviations. 

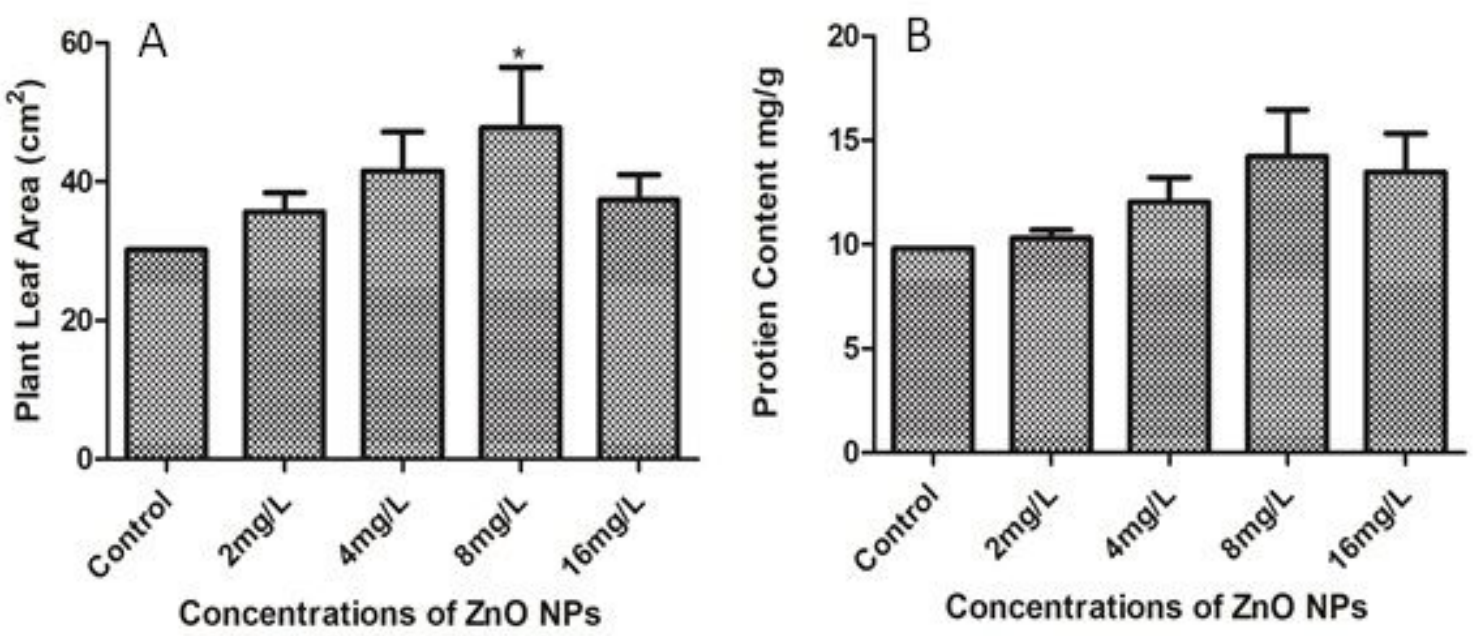

Figure 7

Effect of seed priming of Zea mays $L$ at different concentration of ZnO NPs at 35 DAS. A) Leaf area; B) and total protein contents: Values reported in the figures are means of triplicates with standard deviations. 